\title{
Technical note: Validation of a semi-automated software tool to determine gait-cycle variables in dairy cows
}

\author{
M. Alsaaod, ${ }^{* 1}$ R. Kredel, $†$ B. Hofer, $†$ and A. Steiner* \\ ${ }^{*}$ Clinic for Ruminants, Vetsuisse-Faculty, and \\ †Institute of Sport Science, Faculty of Human Sciences, University of Bern, 3001, Switzerland
}

\begin{abstract}
This paper presents the validation of a software tool called Cow-Gait-Analyzer (University of Bern, Switzerland) to determine gait-cycle variables in lame and non-lame dairy cows using features derived from lowcost, stand-alone 3-dimensional accelerometers (400 $\mathrm{Hz}$ ). The Cow-Gait-Analyzer automatically extracts the relevant gait events of foot load and toe off, which characterize gait-cycle duration, stance phase, and swing phase during walking. A nonautomatic step is visual inspection of the pedograms. If the software does not automatically choose the right peaks according to pedogram definitions, peaks can be manually chosen. We validated the algorithms by comparing the accelerometer data (pedogram) with the synchronized video data, which we used as a gold standard. We carried out the measurements at the metatarsal level of paired hind limbs during walking. We included 12 non-lame cows and 5 lame cows and expressed overall differences between the Cow-Gait-Analyzer and the gold standard as relative measurement error (RME). We analyzed 34 hind limbs with a mean of 9 gait cycles. The median RME for gait-cycle duration and stance phases were 0 and $1.69 \%$, respectively. The peaks of gait-cycle variables showed RME of 0.67 and $0.24 \%$ for foot load and toe off, respectively. The semi-automated Cow-GaitAnalyzer can accurately determine gait-cycle variables in both lame and non-lame cows, and could be used to assess gait patterns in routine clinical and research practice focusing on individual cows.
\end{abstract}

Key words: dairy cow, gait cycle, accelerometer, algorithms

\section{Technical Note}

Automated measures of behavioral-based animal welfare indicators in cattle are highly desirable as

Received October 31, 2016.

Accepted February 9, 2017.

${ }^{1}$ Corresponding author: maher.alsaaod@vetsuisse.unibe.ch practical tools to support human observers (Rushen et al., 2012). One of the most beneficial aspects of automated measures is that they can help observers detect subtle changes in behavior (Van Nuffel et al., 2015). Behavior changes associated with foot pathologies can be quantified using (1) kinematic gait analysis (Flower et al., 2005), such as high-speed cinematography with the cow on a treadmill (Schmid et al., 2009) or image-processing techniques (Poursaberi et al., 2010; Viazzi et al., 2013); or (2) kinetic gait analysis using 1-dimensional or 3-dimensional ground reaction force systems (Rajkondawar et al., 2006; Walker et al., 2010; Thorup et al., 2014) or pressure-sensitive walkways (Van Nuffel et al., 2009; Maertens et al., 2011). For example, weight shifting among legs during standing indicates discomfort and pain associated with lameness (Pastell and Kujala, 2007; Chapinal et al., 2010; Nechanitzky et al., 2016). However, these methods may be expensive, time-consuming, or both, limiting their practical application. Increasing asymmetry in kinematic and kinetic measurements of gait events is a promising indicator for objective diagnostic tests when pathologies are present (Flower and Weary, 2006; Thorup et al., 2014; Alsaaod et al., 2017). Assessment of the stance phase is a promising approach for detecting lameness and foot pathologies in dairy cows using kinematic gait measurement (Flower et al., 2005) and in equines and cattle using accelerometers with a high sampling rate (Olsen et al., 2012; Alsaaod et al., 2017). Using a 3-dimensional accelerometer to detect extended locomotion behavior (Alsaaod et al., 2015) and identify slightly lame cows in dairy herds has been described recently (Beer et al., 2016). The objective of this study was to validate a semi-automated tool, the Cow-GaitAnalyzer, (University of Bern, Switzerland) to extract kinematic (temporal events: gait-cycle duration, stand phase duration, and swing phase duration) and kinetic (peaks: foot load and toe off) variables from the outputs of accelerometers with a high sampling rate at the metatarsal level during walking. We hypothesized that gait-cycle variables could be derived from the CowGait-Analyzer that had a high correlation with results 
from synchronized cinematographic pedograms (gold standard) in lame and non-lame cows.

Twelve dairy cows without any signs of lameness, that were not subjected to abdominal surgery, and that did not have clinical mastitis (non-lame), and 5 cows referred to the Clinic for Ruminants, Vetsuisse-Faculty, University of Bern, for evaluation of a lameness problem in the hind limbs (lame) were used in the study. We rated lameness using a numerical rating system of 1 to 5 (NRS; where $1=$ sound, non-lame, and $5=$ severely lame; Flower and Weary, 2006). The lame group (NRS $\geq 3$ ) included cows with one of the following unilateral pathologies: bulb abscess, double sole, osteitis of P3, septic tendovaginitis of the common digital flexor tendon sheath, or septic arthritis of the tibiotarsal joint. Cows in the lame group had a mean $[ \pm$ standard deviation (SD)] lactation number of $1.2( \pm 0.45)$, a mean daily milk yield of $25.5( \pm 3.32) \mathrm{kg}$, and a mean BW of $546.75( \pm 77.95) \mathrm{kg}$. The breeds involved were Holstein Friesian $(\mathrm{n}=2)$, Red Holstein $(\mathrm{n}=1)$, Brown Swiss $(\mathrm{n}=1)$, and Eringer $(\mathrm{n}=1)$. Cows in the non-lame group $(\mathrm{NRS}<3)$ had a mean $( \pm \mathrm{SD})$ lactation number of $2.58( \pm 1.31)$, a mean daily milk yield of $30.5( \pm 8.87)$ $\mathrm{kg}$, and a mean BW of $632.36( \pm 94.01) \mathrm{kg}$. The breeds involved were Holstein Friesian $(\mathrm{n}=2)$, Red Holstein $(\mathrm{n}=4)$, Swiss Fleckvieh $(\mathrm{n}=5)$, and Rhätisches Grauvieh $(\mathrm{n}=1)$.

All cows were halter-broken when they arrived at the clinic. Cows were also individually guided to walk quietly for 10 to 20 min immediately before each measurement. They were then encouraged by an animal caretaker to walk in a straight line for $>10 \mathrm{~m}$ on an asphalt floor, 3 times (3 walking phases), using 2 stand-alone acceler- ometers (400 Hz; USB Accelerometer X16-4; Gulf Coast Data Concept, Waveland, MS), each attached to 1 hind limb, synchronized with high-speed video camera (120 $\mathrm{Hz}$ ) as described by Alsaaod et al. (2017). We selected a mean of 9 gait cycles using convenience sampling from 3 walking phases per limb pair, after excluding gait cycles that represented running or cycles with signal artifacts (as determined by visual inspection). We processed the raw data from the accelerometers using the software tool Cow-Gait-Analyzer (http://www.wiederkaeuerklinik.unibe.ch), developed by the Institute of Sport Science, Faculty of Human Sciences, University of Bern, Switzerland (Figure 1). This MATLAB-based software tool simplifies analysis by automating most of the steps necessary to extract relevant gait-cycle variables. After the raw data file or folder has been selected, the Cow-Gait-Analyzer automatically filters the raw data with a zero-lag, second-order, low-pass Butterworth filter using an optimal estimate of the cutoff frequency (Winter, 2009), and then graphically displays the 3 -dimensional vector magnitude pedogram (as described by Robert et al., 2009; Chapinal et al., 2011; Alsaaod et al., 2017). If selected, the unfiltered vector magnitude pedogram and the unfiltered accelerations in $\mathrm{X}, \mathrm{Y}$, and $\mathrm{Z}$ dimensions are also displayed. Using graphical sliders, the temporal region of interest can be selected, and calculation of a defined gait-cycle event can be repeated. This is particularly helpful when the sensors' raw data include steps before or after the experimental trial.

Based on the filtered vector magnitude pedogram data, the software tool automatically estimates the gait-cycle events of peak foot load and peak toe off

Table 1. Definitions of the kinematic (temporal) and kinetic (peak) pedogram variables of cows' gait at the level of the metatarsus, including gait phases/complexes, temporal events, and peaks as described by Alsaaod et al. (2017)

\begin{tabular}{|c|c|}
\hline Variable & Definition \\
\hline $\begin{array}{l}\text { Kinematic (temporal) } \\
\text { Gait-cycle duration (s) }\end{array}$ & Interval between 2 consecutive foot-load peaks \\
\hline Swing phase (\%) & $\begin{array}{l}\text { Interval between toe-off peak and consecutive foot-load peak of the same gait cycle of the same limb, } \\
\text { expressed as percentage proportion of the total gait-cycle duration of that limb }\end{array}$ \\
\hline Kinetic (peak) & \\
\hline Foot load (g) & $\begin{array}{l}\text { Maximum peak of the gait initiation complex exerted by a simultaneous peak of the } x \text { - and } y \text {-axis }(+ \text { or }- \\
\text { value) of the accelerogram, corresponding to the initial ground contact of the claw }\end{array}$ \\
\hline
\end{tabular}




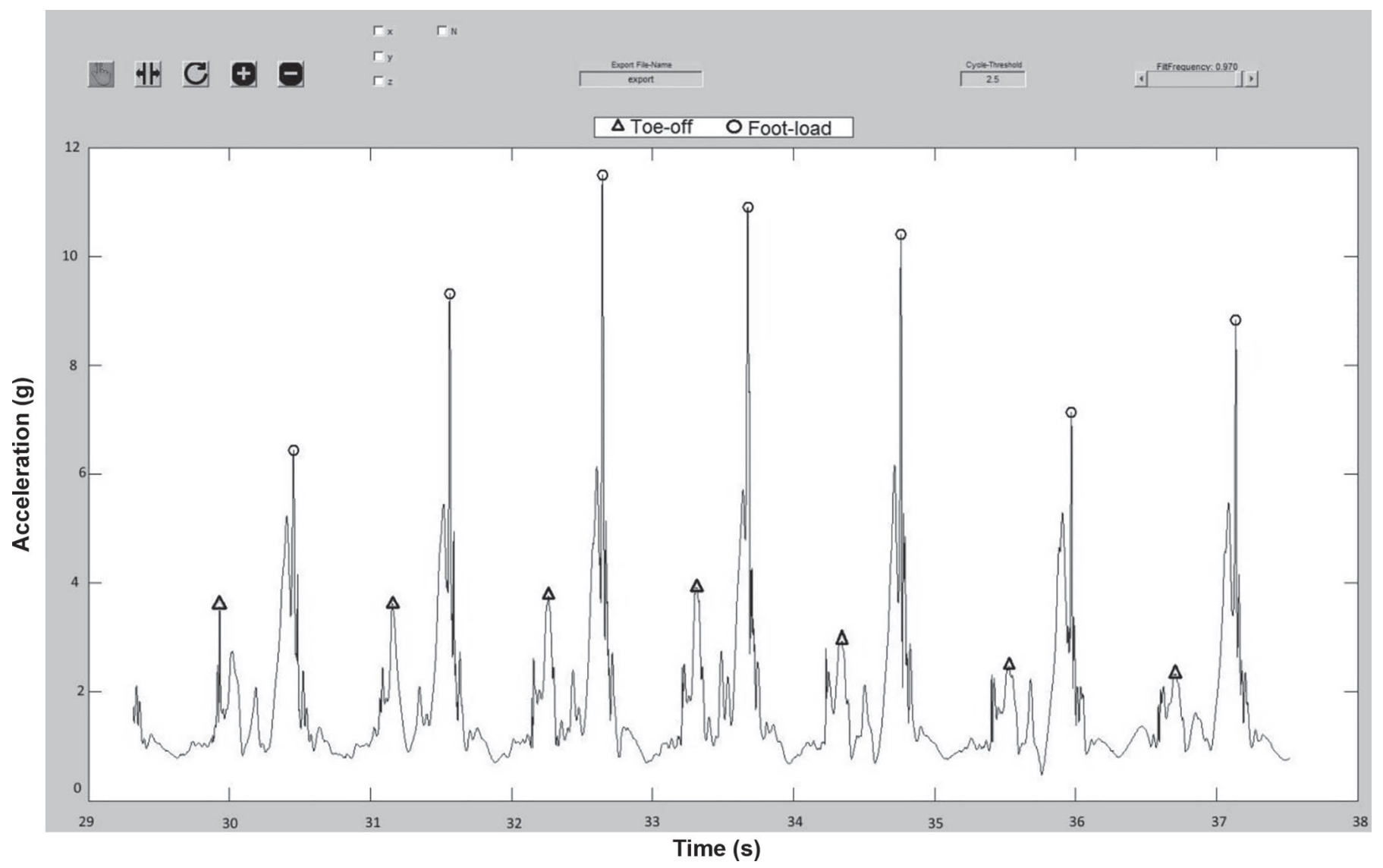

Figure 1. Example of gait-cycle determination using the semi-automated Cow-Gait-Analyzer (University of Bern, Switzerland) for a nonlame cow (Red Holstein, lactation number 1, BW $560 \mathrm{~kg}$ ). Pedogram was derived from stand-alone high sampling (400 Hz) accelerometer at the level of the metatarsus. The circles refer to foot-load peaks, and triangles refer to toe-off peaks.

using a local maxima search (integrated MATLAB function: findpeaks) combined with a semi-automatic threshold for baseline noise (can be changed using a slider in the graphical user interface). The non-automatic step is visual inspection of the pedograms. If the software does not automatically chose the right peaks according to the pedogram definitions (as defined in Table 1), peaks can be modified manually. The defined gait-cycle variables are calculated and exported to an Excel spreadsheet, including time samples and values.

To validate the Cow-Gait-Analyzer, we compared data from the pedograms, visually confirmed using synchronized video data (gold standard) of lame and nonlame cows $(\mathrm{n}=17)$, with the output of the software tool. We calculated relative measurement error (RME) from the difference between the Cow-Gait-Analyzer

Table 2. Descriptive statistics, relative measurement error (RME), and Pearson correlation coefficients $\left(\mathrm{r}_{\mathrm{p}}\right)$ of the kinematic gait-cycle variables (temporal = gait-cycle duration, stance, and swing phase) and kinetics (peaks $=$ foot load and toe off) given by the Cow-Gait-Analyzer (University of Bern, Switzerland) compared with the result of a pedogram synchronized with cinematography (gold standard)

\begin{tabular}{|c|c|c|c|c|c|c|c|}
\hline Variable & \multicolumn{2}{|c|}{ Cow-Gait-Analyzer } & \multicolumn{2}{|c|}{ Gold standard } & \multicolumn{2}{|c|}{ RME (\%) } & $\mathrm{r}_{\mathrm{p}}$ \\
\hline Stance phase $(\%)$ & 65.22 & 7.25 & 64.41 & 6.75 & 1.69 & 1.836 & 0.95 \\
\hline Swing phase (\%) & 34.77 & 7.25 & 35.59 & 6.75 & 1.69 & 1.836 & 0.95 \\
\hline \multicolumn{8}{|l|}{ Kinetic (peak) } \\
\hline
\end{tabular}


A)
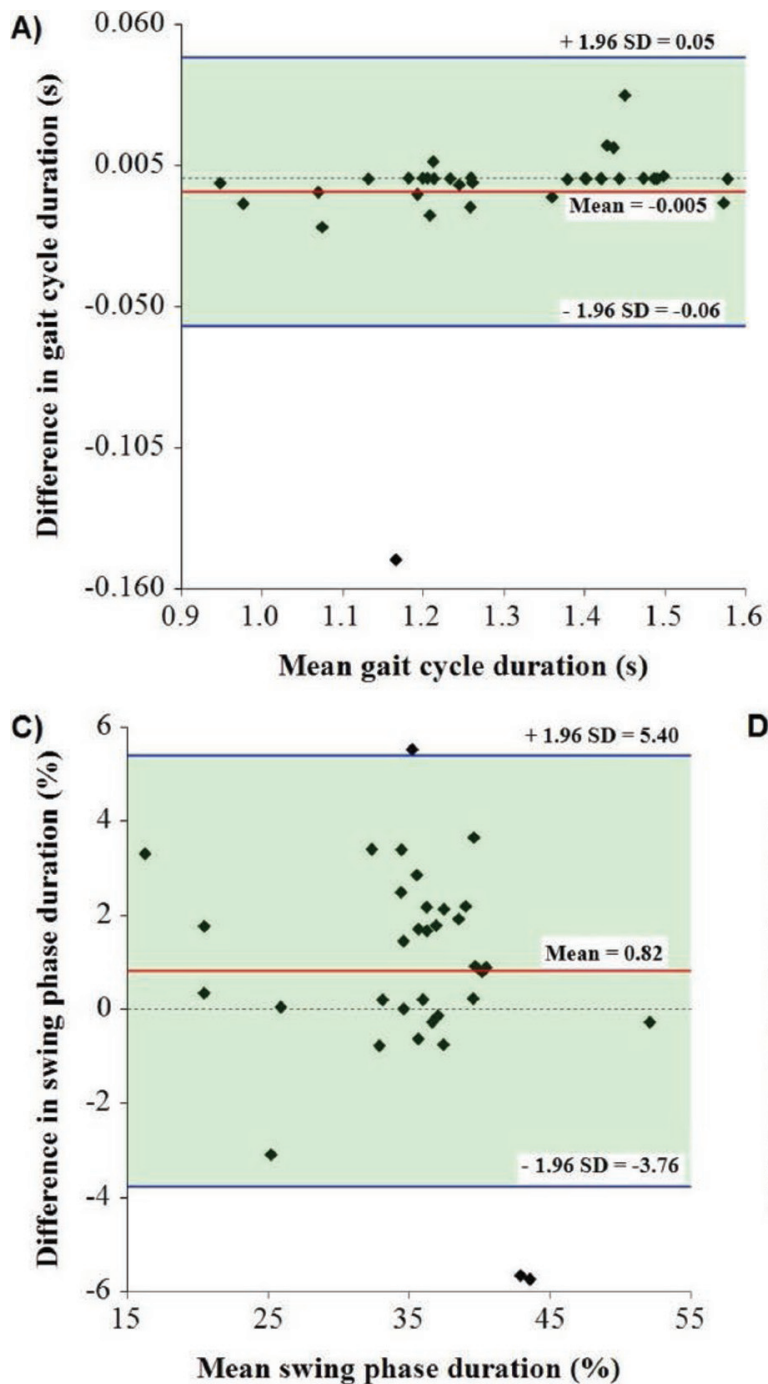

E) $\quad 37$

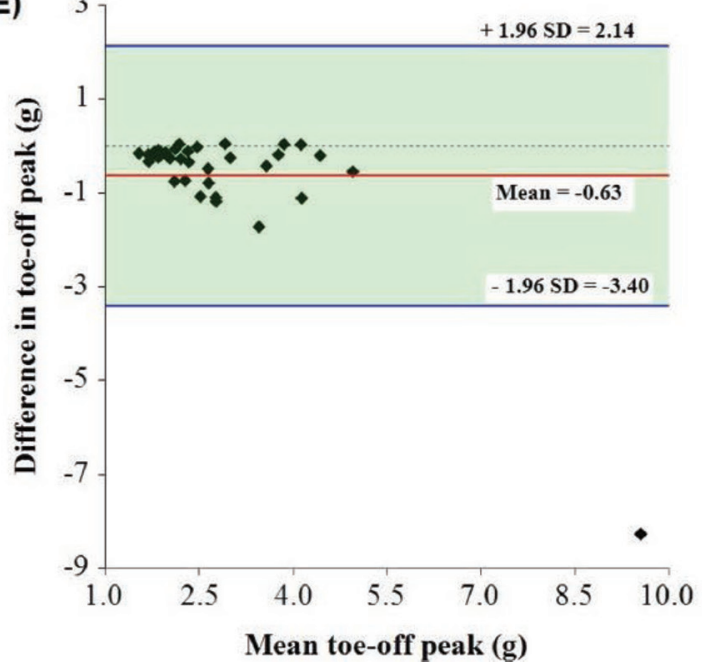

B)

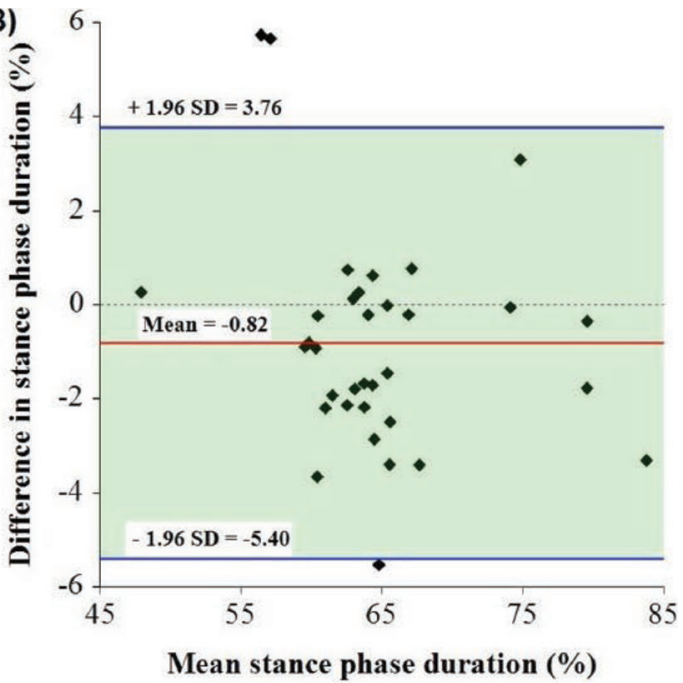

D)

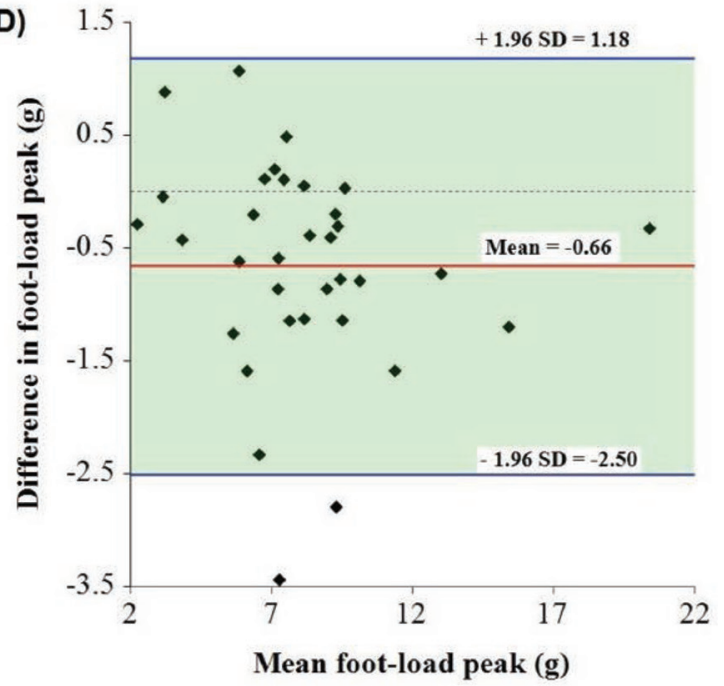

Figure 2. Bland-Altman plots comparing the difference in means (bias) of gait-cycle variables determined by the gold standard (pedogram synchronized with cinematography) and the Cow-Gait-Analyzer (University of Bern, Switzerland) in both lame and non-lame cows: (A) gaitcycle duration (s); (B) stance-phase duration (\%); (C) swing-phase duration (\%); (D) foot-load peak (g); and (E) toe-off peak (g). The upper and lower horizontal lines correspond to the higher and lower $95 \%$ limits of agreement (mean $\pm 1.96 \mathrm{SD}$ ), respectively. Color version available online. 
value (CGA) and the gold standard (GS) using the following formula:

$$
\text { Deviation }(\%)=\frac{100}{\mathrm{GS}} \times \text { absolute value }(\mathrm{GS}-\mathrm{CGA}) \text {. }
$$

We calculated median and mean to describe the RME for the different variables. An RME of $<1 \%$ was very low, and an RME of 1 to $5 \%$ was low. We calculated Pearson correlations to determine the strength of the relationship between data from the Cow-Gait-Analyzer and the gold standard. We also generated a BlandAltman analysis and corresponding plot for gait-cycle variables to determine bias and agreement between the Cow-Gait-Analyzer and the gold standard. We did not consider variability among individual cows, because comparisons between the software tool and the respective gold standard were done at the cow level. The variables from the lame and non-lame groups were not normally distributed, so we used the Wilcoxon nonparametric test to compare the RME values between the 2 groups. All statistical analyses were undertaken using NCSS $^{10}$ (NCSS LLC, Kaysville, UT).

The NRS [means \pm SD (range)] were $1.6 \pm 0.26$ (1.30-2.17) and $3.83 \pm 0.57$ (3.17-4.67) for the nonlame and lame groups, respectively. We observed no significant differences in RME between the 2 groups for any of the variables. The median RME for gait-cycle duration and stance phase were 0 and $1.69 \%$, respectively. The peaks of gait-cycle variables had RME of 0.675 and $0.245 \%$ for foot load and toe off, respectively (Table 2). All gait variables had Pearson correlation coefficients $>0.80$ (Table 2). The Bland-Altman analysis (Figure 2) indicated that most values indicating the differences between the gold standard and the CowGait-Analyzer lay within the $95 \%$ limits of agreement (mean $\pm 1.96 \mathrm{SD}$ ). The values on the Bland-Altman plot were evenly scattered above and below 0 , suggesting no consistent bias for the gold standard versus the Cow-Gait-Analyzer.

In our evaluation, estimates of the kinematic (temporal) and kinetic (peak) pedogram variables showed very low (gait cycle, foot load, toe off) and low (stance phase and swing phase) RME compared with the output of the Cow-Gait-Analyzer and the gold standard. To the best of our knowledge, this is the first description of a software tool that allows gait-cycle variables to be determined with a high degree of accuracy compared with the gold standard. Many studies have reported that a specific algorithm can be created to classify accelerometer raw data into specific behavior categories (Robert et al., 2009; Alsaaod et al., 2015). Algorithms to determine gait events have also been successfully de- veloped in humans (Novak et al., 2013) and horses (Olsen et al., 2012; Starke et al., 2012). We have developed a semi-automated gait analysis tool for cattle. However, determining the kinetic peaks of foot load and toe off requires an understanding of accelerogram definitions, and the peaks should be adjusted exactly according to these definitions. Foot load is mostly perfectly determined, but toe off must be modified manually by an expert (data not available).

An important limitation of the Cow-Gait-Analyzer is that severely lame cows may have different gait patterns than non-lame cows (Tanida et al., 2011; Thorup et al., 2014). However, our results showed no significant differences in extracting gait-cycle variables between the lame and non-lame groups using the Cow-GaitAnalyzer. Furthermore, we performed our evaluation in a controlled manner (i.e., cows walked in a straight line after excluding gait cycles that represented running or that had signal artifacts, as determined by visual inspection).

The semi-automated Cow-Gait-Analyzer can be used to determine gait-cycle variables using $400-\mathrm{Hz} 3$-dimensional accelerometers. The frequency and peaks of foot load and toe off can be adapted and used to extract gait-cycle variables with great accuracy. This successful validation of the Cow-Gait-Analyzer suggests its possible use as a semi-automated tool for research and clinical applications with a focus on individual cows. The Cow-Gait-Analyzer is a promising tool to objectively assess gait in lame and non-lame cows.

\section{ACKNOWLEDGMENTS}

This study was generously supported by grants from Fondation Sur-La-Croix, Basel, Switzerland.

\section{REFERENCES}

Alsaaod, M., M. Luternauer, T. Hausegger, R. Kredel, and A. Steiner. 2017. The cow pedogram-analysis of gait cycle variables allows the detection of lameness and foot pathologies. J. Dairy Sci. 100:1417-1426.

Alsaaod, M., J. J. Niederhauser, G. Beer, N. Zehner, G. SchuepbachRegula, and A. Steiner. 2015. Development and validation of a novel pedometer algorithm to quantify extended characteristics of the locomotor behavior of dairy cows. J. Dairy Sci. 98:6236-6242.

Beer, G., M. Alsaaod, A. Starke, G. Schuepbach-Regula, H. Muller, P. Kohler, and A. Steiner. 2016. Use of extended characteristics of locomotion and feeding behavior for automated identification of lame dairy cows. PLoS One 11:e0155796.

Chapinal, N., A. M. de Passille, M. Pastell, L. Hanninen, L. Munksgaard, and J. Rushen. 2011. Measurement of acceleration while walking as an automated method for gait assessment in dairy cattle. J. Dairy Sci. 94:2895-2901.

Chapinal, N., A. M. de Passille, J. Rushen, and S. Wagner. 2010. Automated methods for detecting lameness and measuring analgesia in dairy cattle. J. Dairy Sci. 93:2007-2013. 
Flower, F. C., D. J. Sanderson, and D. M. Weary. 2005. Hoof pathologies influence kinematic measures of dairy cow gait. J. Dairy Sci. $88: 3166-3173$.

Flower, F. C., and D. M. Weary. 2006. Effect of hoof pathologies on subjective assessments of dairy cow gait. J. Dairy Sci. 89:139-146.

Maertens, W., J. Vangeyte, J. Baert, A. Jantuan, K. C. Mertens, S De Campeneere, A. Pluk, G. Opsomer, S. Van Weyenberg, and A. Van Nuffel. 2011. Development of a real time cow gait tracking and analysing tool to assess lameness using a pressure sensitive walkway: The GAITWISE system. Biosyst. Eng. 110:29-39.

Nechanitzky, K., A. Starke, B. Vidondo, H. Muller, M. Reckardt, K. Friedli, and A. Steiner. 2016. Analysis of behavioral changes in dairy cows associated with claw horn lesions. J. Dairy Sci. 99:2904-2914.

Novak, D., X. Omlin, R. Leins-Hess, and R. Riener. 2013. Predicting targets of human reaching motions using different sensing technologies. IEEE Trans. Biomed. Eng 60:2645-2654.

Olsen, E., P. H. Andersen, and T. Pfau. 2012. Accuracy and precision of equine gait event detection during walking with limb and trunk mounted inertial sensors. Sensors (Basel) 12:8145-8156.

Pastell, M. E., and M. Kujala. 2007. A probabilistic neural network model for lameness detection. J. Dairy Sci. 90:2283-2292.

Poursaberi, A., C. Bahr, A. Pluk, A. Van Nuffel, and D. Berckmans. 2010. Real-time automatic lameness detection based on back posture extraction in dairy cattle: Shape analysis of cow with image processing techniques. Comput. Electron. Agric. 74:110-119

Rajkondawar, P. G., M. Liu, R. M. Dyer, N. K. Neerchal, U. Tasch, A. M. Lefcourt, B. Erez, and M. A. Varner. 2006. Comparison of models to identify lame cows based on gait and lesion scores, and limb movement variables. J. Dairy Sci. 89:4267-4275.

Robert, B., B. J. White, D. G. Renter, and R. L. Larson. 2009. Evaluation of three-dimensional accelerometers to monitor and classify behavior patterns in cattle. Comput. Electron. Agric. 67:80-84.

Rushen, J., N. Chapinal, and A. M. de Passille. 2012. Automated monitoring of behavioural-based animal welfare indicators. Anim. Welf. 21:339-350.
Schmid, T., M. A. Weishaupt, S. W. Meyer, N. Waldern, K. Peinen, and K. Nuss. 2009. High-speed cinematographic evaluation of clawground contact pattern of lactating cows. Vet. J. 181:151-157.

Starke, S. D., T. H. Witte, S. A. May, and T. Pfau. 2012. Accuracy and precision of hind limb foot contact timings of horses determined using a pelvis-mounted inertial measurement unit. J. Biomech. 45:1522-1528.

Tanida, H., Y. Koba, J. Rushen, and A. M. De Passile. 2011. Use of three-dimensional acceleration sensing to assess dairy cow gait and the effects of hoof trimming. Anim. Sci. J. 82:792-800.

Thorup, V. M., O. F. do Nascimento, F. Skjoth, M. Voigt, M. D. Rasmussen, T. W. Bennedsgaard, and K. L. Ingvartsen. 2014. Changes in gait symmetry in healthy and lame dairy cows based on 3-dimensional ground reaction force curves following claw trimming. J. Dairy Sci. 97:7679-7684.

Van Nuffel, A., M. Sprenger, F. A. M. Tuyttens, and W. Maertens. 2009. Cow gait scores and kinematic gait data: Can people see gait irregularities? Anim. Welf. 18:433-439.

Van Nuffel, A., I. Zwertvaegher, L. Pluym, S. Van Weyenberg, V. M. Thorup, M. Pastell, B. Sonck, and W. Saeys. 2015. Lameness detection in dairy cows: Part 1 . How to distinguish between non-lame and lame cows based on differences in locomotion or behavior. Animals (Basel) 5:838-860.

Viazzi, S., C. Bahr, A. Schlageter-Tello, T. Van Hertem, C. E. B. Romanini, A. Pluk, I. Halachmi, C. Lokhorst, and D. Berckmans. 2013. Analysis of individual classification of lameness using automatic measurement of back posture in dairy cattle. J. Dairy Sci. $96: 257-266$.

Walker, A. M., T. Pfau, A. Channon, and A. Wilson. 2010. Assessment of dairy cow locomotion in a commercial farm setting: The effects of walking speed on ground reaction forces and temporal and linear stride characteristics. Res. Vet. Sci. 88:179-187.

Winter, D. A. 2009. Biomechanics and Motor Control of Human Movement. 4th ed. Wiley, Hoboken, NJ. 